\title{
Life expectancy in patients with pituitary adenoma receiving growth hormone replacement
}

\author{
Daniel S Olsson', Penelope Trimpou', Tobias Hallén², Ing-Liss Bryngelsson³, \\ Eva Andersson ${ }^{4}$, Thomas Skoglund ${ }^{2}$, Bengt-Åke Bengtsson', \\ Gudmundur Johannsson ${ }^{1, *}$ and Anna G Nilsson ${ }^{1, *}$ \\ 'Department of Endocrinology, Institute of Medicine, Sahlgrenska Academy, University of Gothenburg \\ and Sahlgrenska University Hospital, Göteborg, Sweden, ${ }^{2}$ Department of Neurosurgery, Sahlgrenska \\ University Hospital, Göteborg, Sweden, ${ }^{3}$ Department of Occupational and Environmental Medicine, \\ Örebro University Hospital, Örebro, Sweden, and ${ }^{4}$ Department of Occupational and Environmental \\ Medicine, Sahlgrenska University Hospital, Göteborg, Sweden \\ *(G Johannsson and A G Nilsson contributed equally to this work)
}

Correspondence should be addressed to D S Olsson

Email

daniel.olsson@gu.se

\begin{abstract}
Objective: Hypopituitarism has been associated with increased mortality. The excess mortality may be due to untreated growth hormone (GH) deficiency but also due to various underlying disorders. We therefore analysed mortality in patients with only one underlying disorder, non-functioning pituitary adenoma (NFPA), with and without GH replacement therapy (GHRT).

Design and method: Patients with NFPA in the western region of Sweden, 1997-2011, were identified through the National Patient Registry and cross-referenced with several National Health Registries. All patient records were reviewed. Standardised mortality ratios (SMRs) with 95\% confidence intervals (Cls) were calculated using the general population as reference. Cox-regression models were performed to identify predictors of mortality.

Results: A total of 426 NFPA patients with 4599 patient-years were included, of whom 207 had used GHRT and 219 had not received GHRT. Median (range) follow-up in patients with and without GHRT was 12.2 (0-25) and 8.2 (0-27) years, respectively. Other pituitary hormone deficiencies were more frequent in the GHRT group than those in the non-GHRT group. SMR was $0.65(95 \% \mathrm{Cl}, 0.44-0.94 ; P=0.018)$ for the GHRT group and $1.16(0.94-1.42 ; P=0.17)$ for the non-GHRT group. Direct comparison between the groups showed reduced mortality among those who were GH replaced $(P=0.0063)$. The SMR for malignant tumours was reduced in the GHRT-group $(0.29 ; 0.08-0.73 ; P=0.004)$ but not in untreated patients.

Conclusions: Selection bias explaining some of the results cannot be excluded. However, NFPA patients with GHRT had reduced overall mortality compared with the general population, and death due to malignancy was not increased. This suggests that long-term GHRT is safe in adult patients selected for treatment.

European Journal of Endocrinology (2017) 176, 67-75
\end{abstract}

\section{Introduction}

Non-functioning pituitary adenomas (NFPAs) are benign tumours without clinical or laboratory evidence of hormone hypersecretion. Instead, they can cause symptoms due to a mass effect on pituitary function, the optic chiasm, and other nearby structures (1). They can also be diagnosed as incidentalomas.
두 2017 European Society of Endocrinology Printed in Great Britain
An increased mortality has been observed for patients with a variety of pituitary disorders compared to the general population, which has in part been explained by hypopituitarism $(2,3,4,5,6,7)$. It has been suggested that the excess mortality in patients with hypopituitarism is caused by inadequate replacement therapy $(4,8)$. Rosén 
and Bengtsson (4) suggested 25 years ago that untreated growth hormone (GH) deficiency (GHD) might be an important factor. The underlying cause of hypopituitarism such as Cushing's disease, craniopharyngioma, or malignant brain tumours per se might also impose increased mortality (7). Recently, it has been suggested that replacement therapy with recombinant GH (GHRT) may reduce the increased mortality previously seen in hypopituitary patients with untreated $\operatorname{GHD}(7,9,10,11$, $12,13)$.

In contrast to small NFPAs, large NFPAs are more likely to cause hypopituitarism and other mass-related complications, leading to surgical treatment. Hence, a proportion of patients with NFPA display intact hormone secretion (3). Only two studies addressing mortality have included patients with NFPA without hypopituitarism $(2,3)$. We have previously shown an excess mortality in women but not in men in an unselected populationbased study of patients with NFPA (3). In that study, the presence of hypopituitarism or previous radiotherapy was associated with an increased risk of premature death. However, the study did not investigate the impact of the degree of hypopituitarism and its replacement therapy on mortality. The aim of this study was to investigate the impact of GHRT on mortality in an unselected group of patients with NFPA in the western region of Sweden.

\section{Subjects and methods}

\section{Study design}

The Swedish National Patient Registry was used to identify all patients who received a diagnosis of NFPA between 1997 and 2011 within the western region of Sweden (Region of Västra Götaland) (3). The registry covers all discharge diagnoses as well as all diagnoses from the outpatient clinics at every hospital in Sweden since 1987. To be included in the study, a patient had to have received the diagnosis of a benign pituitary adenoma (ICD-10 code D35.2) at a department of internal medicine, neurology, or neurosurgery. Patients with endocrine-active adenomas were excluded from the analysis. The medical files of the included patients were reviewed twice by two physicians (D S O and $\mathrm{P} \mathrm{T}$ ) for the confirmation of the diagnosis and for retrieving information on tumour treatment, hormone replacement therapy, body mass index (BMI), and treatment for hypertension. The included patients did not have any clinical or histopathological signs of an endocrine active adenoma. In addition, data on the duration of GH therapy, daily dose of GH, and the most recent assessment of serum insulin-like growth factor 1 (IGF-1) were retrieved. The recommendations of the Growth Hormone Research Society were followed to establish the diagnosis of GHD (14). All patients who went through a diagnostic test and found to be GHD were offered replacement therapy.

All patients with a confirmed diagnosis of NFPA between January 1, 1997, and December 31, 2011, were identified for inclusion in the study. The period was chosen because the ICD-10 classification was implemented in Sweden on January 1, 1997. The patients' outcome was studied either from the day of diagnosis or from the start of the study, which was January 1, 1987, to death or the end of study, which was December 31, 2014. Information on mortality was retrieved from the Swedish National Death Registry, which contains information on the cause of death for all fatalities in Sweden (for ICD10 codes regarding cause-specific mortality, see section on supplementary data given at the end of this article). All cancer diagnoses were collected from the Swedish National Cancer Registry.

The Swedish National Patient Registry, the Swedish Cancer Registry, and the Swedish National Death Registry are all maintained by the Swedish Board of Social Welfare. They have been shown to have high quality and coverage $(15,16,17)$.

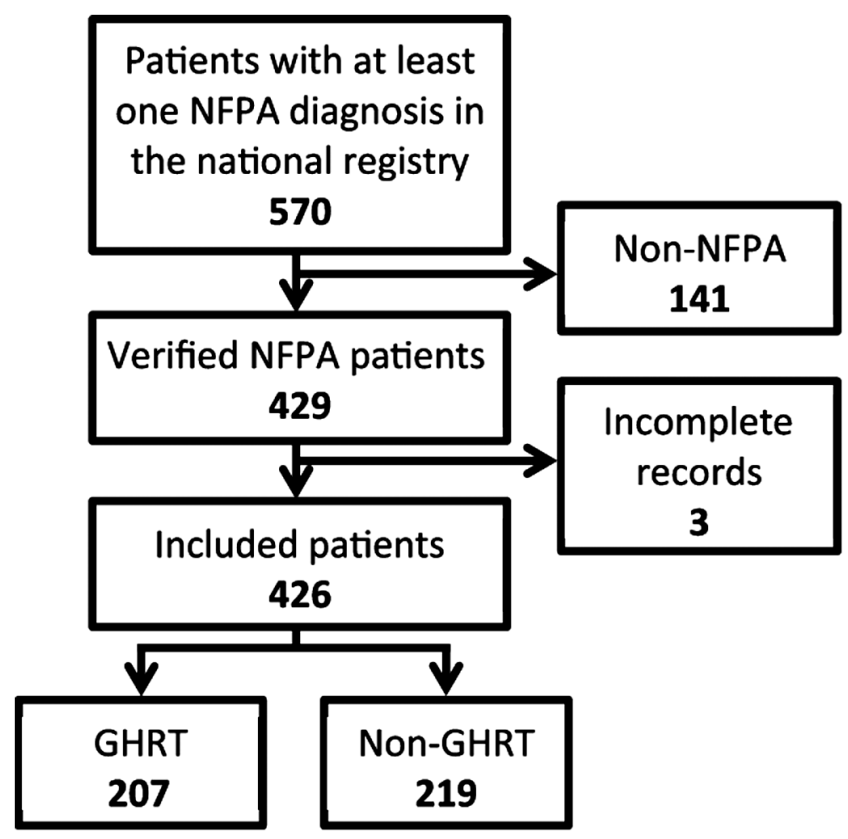

Figure 1

Study design. GHRT, growth hormone replacement therapy; NFPA, non-functioning pituitary adenoma. 


\section{Patients}

The search of the Swedish National Patient Registry identified 570 patients, but 144 were excluded as the diagnosis of NFPA could not be verified in the patient records $(n=141)$ or there were incomplete records for the patients $(n=3)$. The large majority of the excluded patients had other pituitaryrelated diseases, e.g. hormone-secreting adenomas or cysts. A total of 426 patients were included in the study (Fig. 1). The included patients were subdivided into two groups: a 'GHRT group' for patients who had received GH therapy and 'non-GHRT group' for those who had not received GH. The frequency of GHD was considerably lower in the group of untreated patients, which included 25 patients with normal GH secretion according to provocation tests.

\section{Ethics}

Ethical approval for the study was obtained from the Regional Ethical Review Board, Gothenburg University, Sweden.

\section{Statistical analysis}

Person-years at risk were calculated from study inclusion to death or end of study and stratified according to gender, 5-year age groups, and 1-year calendar periods. The expected number of cases for each stratum was calculated using the general Swedish population for every calendar year and 5-year age group as reference. The observed number of cases among patients with NFPA was compared to that expected by standardised mortality ratios (SMRs) and standardised incidence ratios (SIRs). Ninety-five percent confidence intervals (CIs) were calculated assuming a Poisson distribution of the observed numbers. Subgroup analyses for GHRT and gender were performed. If less than two events were observed, no estimate was made for SMR. SMRs for non-overlapping subgroups were compared to each other (18). Additional SMR analysis, with a different definition of baseline was performed.

To study the effect of GHRT on mortality Cox models with duration of treatment as a time dependent variable was used (19). The presence of treatment was included as an updated predictor set to the duration (in years) of treatment each patient had received at the time point being calculated. This allows to adjust for varying amounts of treatment and preserves data that would be lost in other types of analyses such as landmark analysis. Cox proportional hazard models were used to investigate possible relationships between multiple factors, such as gender, starting age in the study, GHRT, radiotherapy, different replacement

Table 1 Baseline characteristics of the study patients.

\begin{tabular}{l}
\hline Characteristics \\
\hline Gender, no. (\%) \\
Men \\
Woman \\
Mean (s.D.) age at the start of \\
study (years) \\
Median (range) follow-up \\
duration (years) \\
Follow-up duration (patient- \\
years) \\
Median (range) GHRT duration \\
(years) \\
GHRT duration (patient-years) \\
Radiotherapy, no. (\%) \\
Surgery, no. (\%) \\
Replacement therapy, no. (\%) \\
Glucocorticoids \\
L-thyroxine \\
Sex steroids \\
Mean (s.D.) body mass index \\
(kg/m²) \\
Treated for hypertension, \\
no./total no. (\%) \\
Deaths, no.
\end{tabular}

Patients with GHRT $(N=207)$
$145(70)$
$62(30)$

$56.3(11.5)$

$12.2(0-24)$

2608

$11.7(0-24)$

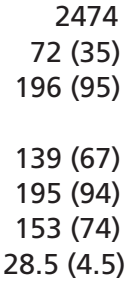

2474

$72(35)$

$96(95)$

$139(67)$

$(94)$

$28.5(4.5)$

$117 / 207(57)$
Patients without GHRT $(N=219)$

$129(59)$

$90(41)$

$65.2(15.0)$

$8.2(0-27)$

1991

-
-
$25(11)$
$112(51)$

$87(40)$
$111(51)$
$81(37)$
$26.5(4.4)$

$114 / 218(52)$

\section{3}

\begin{tabular}{c}
\hline $\boldsymbol{P}$ value \\
\hline 0.02 \\
$<0.001$ \\
$<0.001$
\end{tabular}

29
$<0.001$
$<0.001$

0.44

a Surgical route was transsphenoidal in $79 \%$, transcranial in $19 \%$ and unknown in $2 \%$ of all patients during their primary surgery; ${ }^{b}$ missing data in $9.9 \%$ of the cases; ' missing data in $<1 \%(n=1)$ of the cases in the group without GHRT.

GHRT, growth hormone replacement therapy. 
Table 2 Mortality data.

\begin{tabular}{|c|c|c|c|c|}
\hline Outcome & Expected no. of deaths & Observed no. of deaths & $\begin{array}{c}\text { Standardised mortality } \\
\text { ratio }(95 \% \mathrm{Cl})\end{array}$ & $P$ value \\
\hline \multicolumn{5}{|l|}{ Overall mortality } \\
\hline All patients & 124.6 & 122 & $0.98(0.81-1.17)$ & 0.86 \\
\hline Men & 85.5 & 82 & $0.96(0.76-1.19)$ & 0.76 \\
\hline Women & 39.1 & 40 & $1.02(0.73-1.39)$ & 0.93 \\
\hline $\mathrm{GHRT}^{\mathrm{a}}$ & 44.4 & 29 & $0.65(0.44-0.94)$ & 0.018 \\
\hline Men & 33.2 & 21 & $0.63(0.39-0.97)$ & 0.032 \\
\hline Women & 11.2 & 8 & $0.71(0.31-1.41)$ & 0.43 \\
\hline Non-GHRTa & 80.2 & 93 & $1.16(0.94-1.42)$ & 0.17 \\
\hline Men & 52.3 & 61 & $1.17(0.89-1.50)$ & 0.26 \\
\hline Women & 27.9 & 32 & $1.15(0.78-1.62)$ & 0.49 \\
\hline \multicolumn{5}{|c|}{$\begin{array}{l}\text { Cause-specific mortality } \\
\text { Infectious diseases (Chapter 1) }\end{array}$} \\
\hline GHRT & 0.8 & 1 & - & - \\
\hline Non-GHRT & 1.5 & 3 & $2.05(0.42-6.00)$ & 0.36 \\
\hline \multicolumn{5}{|c|}{ Circulatory diseases (Chapter 9) } \\
\hline GHRT & 16.6 & 13 & $0.78(0.42-1.34)$ & 0.45 \\
\hline Non-GHRT & 36.5 & 40 & $1.10(0.78-1.49)$ & 0.60 \\
\hline \multicolumn{5}{|c|}{ Ischaemic heart disease } \\
\hline GHRT & 8.3 & 7 & $0.84(0.34-1.73)$ & 0.81 \\
\hline Non-GHRT & 16.6 & 13 & $0.79(0.42-1.34)$ & 0.46 \\
\hline \multicolumn{5}{|c|}{ Cerebrovascular disease } \\
\hline GHRT & 3.2 & 3 & $0.90(0.19-2.63)$ & 0.99 \\
\hline Non-GHRT & 7.9 & 14 & $1.78(0.97-2.99)$ & 0.060 \\
\hline \multicolumn{5}{|c|}{ Malignant neoplasms } \\
\hline All patients & 31.6 & 21 & $0.67(0.41-1.02)$ & 0.061 \\
\hline GHRT & 14.0 & 4 & $0.29(0.08-0.73)$ & 0.004 \\
\hline Non-GHRT & 17.5 & 17 & $0.97(0.56-1.55)$ & 0.99 \\
\hline
\end{tabular}

Chapters refer to the ICD-10 classification.

aStandard mortality ratio significantly $(P=0.009)$ different between patients with and without GHRT.

GHRT, growth hormone replacement therapy.

therapy, BMI, and hypertension and mortality. A final Cox model was reached through forward selection of significant variables. The possible effect of the length of GHRT (less than 2, 5, 7 or 10 years) on mortality was also investigated using Cox models with time-dependent variables. The proportional hazard assumption was checked. A Kaplan-Meier plot was also used to present the unadjusted survival (Supplementary Fig. 1). Information was gathered from Statistics Sweden to plot the two control groups in the Kaplan-Meier graph.

Potential differences in the GH regimen between patients who were alive or had died during the study were investigated by analysing IGF-1 level, IGF-1 s.D. score, and GH dose at last follow-up. Student's t-test and Mann-Whitney $U$ test were used for comparisons between groups with continuous variables with normal and skewed distribution, respectively. Chi-square test was performed for comparison between groups with dichotomous variables. The level of significance was set to $P<0.05$. IBM SPSS (version 21) and STATA SE (version 12.1) software was used to perform study analyses.

\section{Results}

\section{Patient characteristics}

A total of 207 patients with NFPA had received GHRT and 219 had not. There were 70\% and 59\% men in the treated and untreated groups, respectively (Table 1). Treated patients were younger, had longer follow-up, higher BMI and were more likely to have received radiotherapy (Table 1). Replacement therapy with cortisol, levothyroxine, and sex steroids was more frequent among patients with GHRT compared to untreated patients.

\section{Overall mortality}

In the whole group, mortality was similar to that of the background population (Table 2), with an SMR of 0.98 (95\% CI: $0.81-1.17 ; P=0.86$ ). The mortality in patients receiving GHRT was decreased (SMR, 0.65; 95\% CI: 0.44$0.94 ; P<0.018)$ and the untreated patients had an SMR of 1.16 (95\% CI: 0.94-1.42; $P=0.17$ ) (Fig. 2B). In a direct comparison between the SMRs of the groups, there was a 


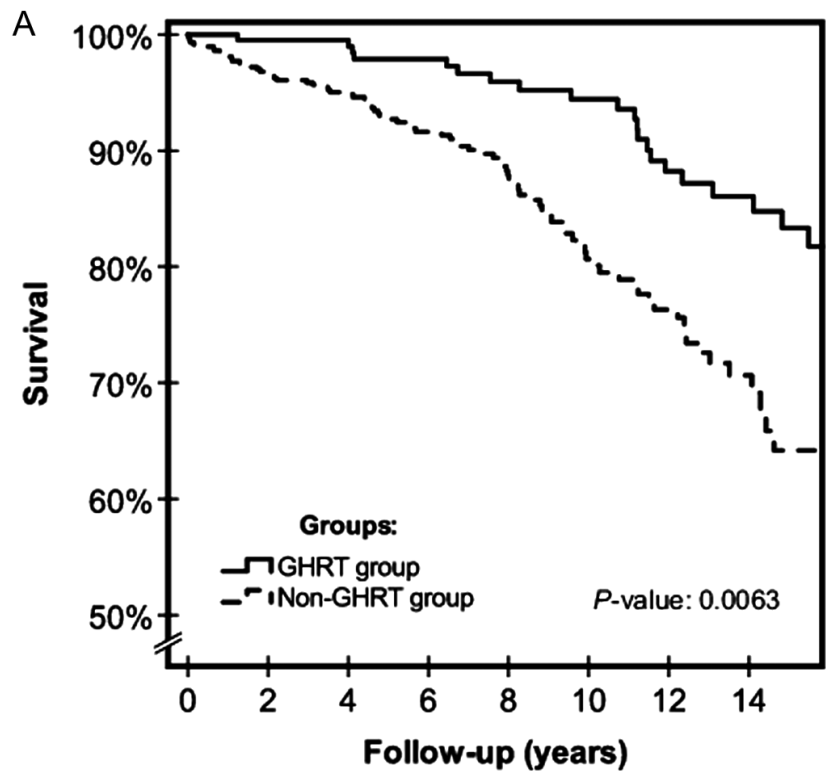

B

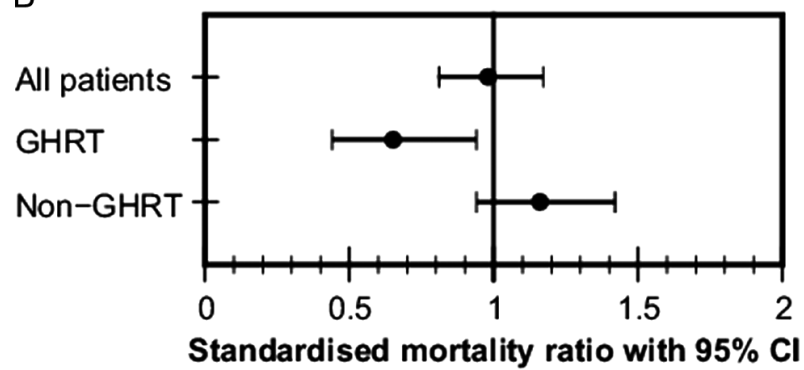

Figure 2

Patient survival. (A) Age-adjusted survival curves differ significantly $(P=0.0063)$ between patients with nonfunctioning pituitary adenoma receiving growth hormone replacement therapy (GHRT) or not (non-GHRT). (B) Standardised mortality ratio for all patients $(n=426)$ with non-functioning pituitary adenoma and in those receiving GHRT ( $n=207)$ or not receiving GHRT $(n=219)$. SMR was significantly lower in patients receiving GHRT compared to the general population $(P=0.018)$ and compared to patients not receiving GHRT $(P=0.009)$.

lower mortality in treated compared to untreated patients $(P=0.009)$.

Both the full and the final Cox model included the significant variables GHRT and starting age in the study. The final Cox model included two variables and revealed a decreased mortality with years of GHRT (hazard ratio (HR) $0.94,95 \%$ CI $0.91-0.98, P=0.0063)$, while increased with age at start in the study (HR 1.10, 95\% CI 1.08-1.12, P<0.0001). Other factors, such as treatment with radiotherapy, BMI, gender and different replacement therapies, did not have a significant effect in the Cox model, and were therefore not selected for the final statistical model. When analysing the effect of the duration of GHRT, no breaking point was found, all levels (less than 2 years, 5 years, 7 years and 10 years) of duration of GHRT treatment were significantly associated with a decreased mortality. An age-adjusted survival curve of the treated and untreated patients is presented in Fig. 2A and an unadjusted Kaplan-Meier plot is supplied in Supplementary Fig. 1.

An additional analysis was performed to further strengthen the method of inclusion in the study, in which the starting date of the study was set to January 1, 1997. The SMR of the GHRT group (0.68; 95\% CI, 0.45-0.97; $P=0.031)$ was consistent with the findings mentioned previously using January 1,1987 , as study start.

Serum concentrations of IGF-1, IGF-1 s.D. scores and the given doses of GH were similar between GHRT patients who were alive and those who died during the study period (Table 3).

\section{Disease-specific cause of death}

The risk of death due to circulatory diseases was not significantly different compared to the general population for the GHRT group (SMR, 0.78; 95\% CI, 0.42-1.34; $P=0.45$ ) or the untreated patients (SMR, 1.10; 95\% CI, $0.78-1.49 ; P=0.60$ ) (Table 2). A separate analysis for mortality from ischaemic heart disease and cerebrovascular disease showed normal SMR in both groups, expect for cerebrovascular disease in untreated patients which showed a tendency to be elevated (SMR 1.78, 95\% CI, 0.97-2.99). A more detailed analysis of the 17 deaths from cerebrovascular diseases showed that three of the patients had received GHRT (1 cerebral haemorrhage, 1 cerebral infarction and 1 further sub-classification not possible) and 14 had not received GHRT (3 cerebral haemorrhage, 4 cerebral infarctions and 7 further sub-classification not possible). Six patients (three in the GHRT group and three in the non-GHRT group) who died from cerebrovascular disease had been treated with radiotherapy. Death from malignant neoplasms was significantly reduced in the treated group, but normal in the untreated patients (Table 2). Details on the types of malignant neoplasms causing death are listed in the Supplementary Table 1.

\section{Incidence of malignant tumours}

The observed number of malignant tumours was 74 for all patients in the study compared to the expected number 
Table 3 Serum IGF-1 level, IGF-1 s.D. scores, and growth hormone dose in patients receiving GHRT.

\begin{tabular}{|c|c|c|c|}
\hline Parameter & Alive & Dead & $P$ value \\
\hline Mean \pm s.D. IGF-1 ( $\mu \mathrm{g} / \mathrm{L})$ & $161 \pm 60$ & $141 \pm 63$ & 0.09 \\
\hline Mean \pm s.D. IGF-1 s.D. score & $0.29 \pm 1.1$ & $0.21 \pm 1.1$ & 0.70 \\
\hline Median (range) growth hormone dose ${ }^{a}$ & $0.36(0.1-1.5)$ & $0.32(0.1-1.0)$ & 0.22 \\
\hline
\end{tabular}

apresented as median (range) as not normally distributed.

GHRT, growth hormone replacement therapy; IGF-1, insulin-like growth factor-1.

of 72.0, which resulted in an SIR of 1.03 (95\% CI, 0.81$1.29 ; P=0.84)$. The SIRs for malignant tumours in patients receiving GHRT and in the untreated patients were 0.98 (95\% CI, 0.69-1.36; $P=0.99)$ and $1.08(0.76-1.48 ; P=0.69)$, respectively.

\section{Discussion}

The use of GHRT in adults with GHD has been shown to result in beneficial effects on body composition, several cardiovascular risk factors, bone density, and quality of life $(20,21,22,23)$. One of the most common causes of GHD in adults is pituitary adenoma, especially NFPA. This study is the first to evaluate mortality in a geographical area where all patients with a diagnosis of NFPA were identified. The data were obtained directly from medical files allowing detailed information in all patients. This study shows a reduced mortality ratio in patients selected for long-term GHRT compared with the general population, suggesting that the treatment has no detrimental effects on mortality. In addition, this study demonstrates that the current clinical management of patients with NFPA results in a normalisation of their life expectancy.

Studies based on cohorts from tertiary centres and post-marketing surveillance databases on adult patients receiving long-term GHRT have shown that the previous excess mortality in hypopituitary patients is not as prominent as before $(7,9,11,12,13)$. Apart from the risk of patient selection in studies from tertiary centres and in post-marketing databases, all these studies have included a wide range of aetiologies for hypopituitarism and GHD. The heterogeneous aetiology of GHD has, thus, been an important confounder in all studies conducted so far.

A recent meta-analysis showed that hypopituitary patients receiving GHRT had an SMR of 1.15 whereas patients without GHRT had an SMR of 2.40 (12). The studies included had a mix of aetiologies of hypopituitarism, including diseases with a known high mortality such as Cushing's disease and craniopharyngioma (7). Only two studies investigating mortality have included unselected populations of patients with NFPA $(2,3)$. Nilsson et al. (2) included patients between 1958 and 1991 and showed an SMR of 2.0 in NFPA patients, whereas it was substantially lower (SMR, 1.1) in a more recent nationwide study also from Sweden including patients between 1987 and 2011 (3). This suggests that overall care of patients with NFPA has improved.

Increased GH and IGF-1 signalling is related to reduced life-expectancy in animal studies (24) but, contrarily, it has also been hypothesised that reduced GH in humans may be related to reduced life span (25). For example, GH receptor gene-disrupted or -knockout mice have an increased life span and are resistant to malignancies (26). Overwhelming evidence from animal and laboratory studies has shown that the GH and IGF-1 axis is implicated in the development and progression of different types of tumours $(27,28,29)$. Furthermore, high normal serum concentrations of IGF-1 and IGF-binding protein 3 in humans have been associated with a moderate increased risk of different cancer types, i.e. prostate, premenopausal breast, and colorectal cancer, in population-based studies (30). It has therefore been suggested that GHRT might increase the risk of death due to malignancy. Our study does not lend support to this notion as, we report a decreased mortality due to malignancies in patients receiving long-term GHRT compared to the general population. In addition, the incidence of malignancies was comparable between treated and untreated patients. A recent Danish study, including patients with various causes of adult onset GHD, also suggested a lower mortality from malignancies in patients with GHRT compared to patients without GHRT (11). Another Danish study in childhood-onset GHD found similar results; reduced risk of death in malignant tumours in patients receiving GHRT than in untreated patients (13). The most likely explanation for these results is the selection of patients for long-term GHRT although this cannot be proven from the available data.

Several studies have demonstrated that GH deficiency is associated with several known risk factors for cardiovascular disease (31). Replacement therapy with GH has been shown to improve many of these factors. This 
has also led to an increased awareness of cardiovascular risk factors in the management and follow-up of hypopituitary patients. Therefore, GHRT as well as the increased awareness and management of cardiovascular disease may contribute to a normalised mortality. Our current study supports that by reporting a risk of deaths from circulatory diseases in the GHRT group that is comparable to the expected frequency (SMR, 0.78; 95\% CI, 0.42-1.34; $P=0.45)$.

Significantly more patients in the GHRT group had received radiotherapy; they had more severe hypopituitarism and increased BMI compared to untreated patients. All these factors suggest that a selection bias of including patients with more severe hypopituitarism as well as higher metabolic burden for GHRT. Despite this, mortality was not increased in the GHRT-group. These results are in contrast with previous nationwide population-based studies from our centre, where hypopituitarism and radiotherapy were associated with a higher mortality ratio in patients with NFPA (3) and craniopharyngioma (32), but it was not possible to establish the prevalence of GHRT in these studies. The improved outcome in patients with GHRT despite evidence of more severe pituitary disease, shown in the present study, may support the importance of GHRT. It could also be argued that patients selected for long-term GHRT are managed by centres with special interest in pituitary diseases, that are able to offer a multidisciplinary care of these patients' hypopituitarism and their underlying disorder. Therefore, an improved overall care of hypopituitary patients is likely to be of importance for their improved outcome.

The limitations of the study include the risk of selection bias as the non-treated group had a higher age at diagnosis and had less severe hypopituitarism. However, the method, SMR, used for estimating the mortality ratio takes age into account, when calculating the estimated number of deaths. Every patient contributes with personyears for every calendar year within their 5-year age group at that year. The mortality ratio from the general population with the same age and gender that calendar year is used as reference. Therefore, the difference in age at study start does not affect the comparison. Also, in the analysis of the survival with Cox models, age at study start was included as a regular covariate to adjust for age effects. Cox models were also computed with age as piecewise linear covariates but this was not found to have any significant impact on the primary result (i.e. the effect of GHRT treatment). All presented survival curves are adjusted for age at study start, except for the unadjusted
Kaplan-Meier plot in the Supplementary Fig. 1. Although important potential confounders such as other pituitary deficiencies, radiotherapy, BMI, hypertension, and incidence of malignant tumours were analysed, there could be other potential confounders that were not analysed in this study. If a substantial portion of patients were withheld from GHRT due to on-going active malignancies, it would transfer mortality due to cancer to the untreated group. However, the incidence of malignancies was not higher in the treated than the untreated patients, the risk of death from malignancy was reduced in the GHRT group and it was not increased in the non-GHRT group, which would be expected if malignancy was the reason for not receiving GHRT. Furthermore, the GHRT group included all patients who had received GHRT, i.e., even if GHRT was withdrawn because a malignant tumour was diagnosed, for example. Despite all this, a more intensive surveillance in the GHRT group may have occurred and as such contributed to the inconsistency between the normal incidence ratio and decreased mortality ratio for malignant diseases seen in the GHRT group. Additionally, there is a possibility that the GHRT group may have been more thoroughly followed than the untreated group with surveillance and treatment of their hypopituitarism as well as comorbidities.

The strengths of the study are that all patients had the same aetiology of pituitary disease, NFPA and that all patients with NFPA within a geographical area were included, resulting in an unselected cohort of patients. In addition, the median duration of GHRT was long, over 10 years (2474 patients-years). Also, the outcome of patients treated with GHRT was compared not only to the general population but also against a group with the same pituitary diagnosis.

In conclusion, this study reports a mortality ratio in patients with NFPA who received long-term GHRT that is similar or even decreased as compared with the background population. Also, the risk of death due to malignant tumours was not increased in NFPA patients receiving GHRT.

\section{Supplementary data}

This is linked to the online version of the paper at http://dx.doi.org/10.1530/ EJE-16-0450.

\section{Declaration of interest}

T H, E A, T S, I-L B, P T and B Å-B have nothing to disclose. D S O has served as a consultant to Pfizer, Sandoz, Ipsen and Novartis and has received lecture fees from Pfizer. G J has served as a consultant to Viropharma/Shire and Astra Zeneca, and has received lecture fees from Pfizer, NovoNordisk, 
and Otsuka. A G N has served as a consultant to Viropharma/Shire and received lecture fees from Astra Zeneca, Novartis and Renapharma.

\section{Funding}

This study was supported in part by the Swedish government under an ALF agreement and the Gothenburg Growth Hormone database has been partly supported through unrestricted grants from Sandoz, NovoNordisk and Pfizer.

\section{Role of the sponsors}

The sponsors did not take part in any manner in the design and conduct of the study, in the collection, management, analysis and interpretation of data or in the writing and the decision to submit the manuscript.

\section{Author contribution statement}

All authors took part in the design of the study. D S O performed the patient selection process and data collection. D S O and I-L B managed the incidences in the general population. D S O designed the figures. D S $\mathrm{O}$ and $\mathrm{P}$ T have reviewed all the patient records in the cohort. All authors contributed to data interpretation and analysis and in writing and revision of the report. All authors are responsible for the integrity of the data and accuracy of the analysis, and all approved the final report.

\section{Acknowledgements}

The authors are indebted to the staff at the Centre for Endocrinology and Metabolism at the Department of Endocrinology at Sahlgrenska University Hospital and to The National Board of Health and Welfare for their excellent collaboration. The authors would like to acknowledge all the help we have received from Statistiska Konsultgruppen, Gothenburg, Sweden, which has performed the mortality calculations. They also would like to thank Peter Todd (Tajut Ltd., Kaiapoi, New Zealand) for third-party writing assistance in drafting of this manuscript, for which he received financial compensation from ALF funding.

\section{References}

1 Greenman Y \& Stern N. Non-functioning pituitary adenomas. Best Practice and Research Clinical Endocrinology and Metabolism 200923 625-638. (doi:10.1016/j.beem.2009.05.005)

2 Nilsson B, Gustavasson-Kadaka E, Bengtsson BA \& Jonsson B. Pituitary adenomas in Sweden between 1958 and 1991: incidence, survival, and mortality. Journal of Clinical Endocrinology and Metabolism 200085 1420-1425. (doi:10.1210/jc.85.4.1420)

3 Olsson DS, Nilsson AG, Bryngelsson IL, Trimpou P, Johannsson G \& Andersson E. Excess mortality in women and young adults with nonfunctioning pituitary adenoma: a Swedish nationwide study. Journal of Clinical Endocrinology and Metabolism 2015100 2651-2658. (doi:10.1210/jc.2015-1475)

4 Rosen T \& Bengtsson BA. Premature mortality due to cardiovascular disease in hypopituitarism. Lancet 1990336 285-288. (doi:10.1016/0140-6736(90)91812-O)

5 Bulow B, Hagmar L, Mikoczy Z, Nordstrom CH \& Erfurth EM. Increased cerebrovascular mortality in patients with hypopituitarism. Clinical Endocrinology 199746 75-81. (doi:10.1046/j.1365-2265.1997. d01-1749.x)

6 Tomlinson JW, Holden N, Hills RK, Wheatley K, Clayton RN, Bates AS, Sheppard MC \& Stewart PM. Association between premature mortality and hypopituitarism. West Midlands Prospective
Hypopituitary Study Group. Lancet 2001357 425-431. (doi:10.1016/ S0140-6736(00)04006-X)

7 Gaillard RC, Mattsson AF, Akerblad AC, Bengtsson BA, Cara J, Feldt-Rasmussen U, Koltowska-Haggstrom M, Monson JP, Saller B, Wilton P et al. Overall and cause-specific mortality in GH-deficient adults on GH replacement. European Journal of Endocrinology 2012166 1069-1077. (doi:10.1530/EJE-11-1028)

8 Burman P, Mattsson AF, Johannsson G, Hoybye C, Holmer H, Dahlqvist P, Berinder K, Engstrom BE, Ekman B, Erfurth EM et al. Deaths among adult patients with hypopituitarism: hypocortisolism during acute stress, and de novo malignant brain tumors contribute to an increased mortality. Journal of Clinical Endocrinology and Metabolism 201398 1466-1475. (doi:10.1210/jc.2012-4059)

9 van Bunderen CC, van Nieuwpoort IC, Arwert LI, Heymans MW, Franken AA, Koppeschaar HP, van der Lely AJ \& Drent ML. Does growth hormone replacement therapy reduce mortality in adults with growth hormone deficiency? Data from the Dutch National Registry of Growth Hormone Treatment in adults. Journal of Clinical Endocrinology and Metabolism 201196 3151-3159. (doi:10.1210/ jc.2011-1215)

10 Hartman ML, Xu R, Crowe BJ, Robison LL, Erfurth EM, Kleinberg DL, Zimmermann AG, Woodmansee WW, Cutler GB Jr, Chipman JJ et al. Prospective safety surveillance of GH-deficient adults: comparison of GH-treated vs untreated patients. Journal of Clinical Endocrinology and Metabolism 201398 980-988. (doi:10.1210/jc.2012-2684)

11 Stochholm K, Berglund A, Juul S, Gravholt CH \& Christiansen JS. Socioeconomic factors do not but GH treatment does affect mortality in adult-onset growth hormone deficiency. Journal of Clinical Endocrinology and Metabolism 201499 4141-4148. (doi:10.1210/ jc.2014-1814)

12 Pappachan JM, Raskauskiene D, Kutty VR \& Clayton RN. Excess mortality associated with hypopituitarism in adults: a meta-analysis of observational studies. Journal of Clinical Endocrinology and Metabolism 2015100 1405-1411. (doi:10.1210/jc.2014-3787)

13 Berglund A, Gravholt CH, Olsen MS, Christiansen JS \& Stochholm K. Growth hormone replacement does not increase mortality in patients with childhood-onset growth hormone deficiency. Clinical Endocrinology 201583 677-683. (doi:10.1111/cen.12848)

14 Ho KK \& 2007 GH Deficiency Consensus Workshop Participants. Consensus guidelines for the diagnosis and treatment of adults with GH deficiency II: a statement of the GH Research Society in association with the European Society for Pediatric Endocrinology, Lawson Wilkins Society, European Society of Endocrinology, Japan Endocrine Society, and Endocrine Society of Australia. European Journal of Endocrinology 2007 157 695-700. (doi:10.1530/EJE-07-0631)

15 Johansson LA. Dödsorsaksstatistik - Historik, Produktionsmetoder och Tillförlitlighet, $\mathrm{p}$ 38. The National Board of Health and Welfare webpage, 2010.

16 Ludvigsson JF, Andersson E, Ekbom A, Feychting M, Kim JL, Reuterwall C, Heurgren M \& Olausson PO. External review and validation of the Swedish national inpatient register. BMC Public Health 201111 450. (doi:10.1186/1471-2458-11-450)

17 Barlow L, Westergren K, Holmberg L \& Talback M. The completeness of the Swedish Cancer Register: a sample survey for year 1998. Acta Oncologica 200948 27-33. (doi:10.1080/02841860802247664)

18 Altman DG \& Bland JM. Interaction revisited: the difference between two estimates. BMJ 2003326 219. (doi:10.1136/bmj.326.7382.219)

19 Cantor AB. SAS Survival Analysis Techniques for Medical Research, Second Edition. Cary, NC, USA: SAS Institute Inc., 2003.

20 Bengtsson BA, Brummer RJ, Eden S, Rosen T \& Sjostrom L. Effects of growth hormone on fat mass and fat distribution. Acta Paediatrica Supplement 1992383 62-65; discussion 66.

21 Burman P, Broman JE, Hetta J, Wiklund I, Erfurth EM, Hagg E \& Karlsson FA. Quality of life in adults with growth hormone $(\mathrm{GH})$ deficiency: response to treatment with recombinant human $\mathrm{GH}$ in a 
placebo-controlled 21-month trial. Journal of Clinical Endocrinology and Metabolism 199580 3585-3590. (doi:10.1210/jcem.80.12.8530603)

22 Gotherstrom G, Bengtsson BA, Bosaeus I, Johannsson G \& Svensson J. A 10-year, prospective study of the metabolic effects of growth hormone replacement in adults. Journal of Clinical Endocrinology and Metabolism 200792 1442-1445. (doi:10.1210/ jc.2006-1487)

23 Appelman-Dijkstra NM, Claessen KM, Roelfsema F, Pereira AM $\&$ Biermasz NR. Long-term effects of recombinant human GH replacement in adults with GH deficiency: a systematic review. European Journal of Endocrinology 2013169 R1-R14. (doi:10.1530/EJE12-1088)

24 Berryman DE, Christiansen JS, Johannsson G, Thorner MO \& Kopchick JJ. Role of the GH/IGF-1 axis in lifespan and healthspan: lessons from animal models. Growth Hormone and IGF Research 2008 18 455-471. (doi:10.1016/j.ghir.2008.05.005)

25 Nass R, Johannsson G, Christiansen JS, Kopchick JJ \& Thorner MO. The aging population - is there a role for endocrine interventions? Growth Hormone and IGF Research 200919 89-100. (doi:10.1016/j. ghir.2008.09.002)

26 Junnila RK, List EO, Berryman DE, Murrey JW \& Kopchick JJ. The GH/ IGF-1 axis in ageing and longevity. Nature Reviews Endocrinology 2013 9 366-376. (doi:10.1038/nrendo.2013.67)
27 Perry JK, Liu DX, Wu ZS, Zhu T \& Lobie PE. Growth hormone and cancer: an update on progress. Current Opinion in Endocrinology, Diabetes, and Obesity 201320 307-313.

28 Pollak M. Insulin and insulin-like growth factor signalling in neoplasia. Nature Reviews Cancer 20088 915-928. (doi:10.1038/ nrc2536)

29 Clayton PE, Banerjee I, Murray PG \& Renehan AG. Growth hormone, the insulin-like growth factor axis, insulin and cancer risk. Nature Reviews Endocrinology 20117 11-24. (doi:10.1038/nrendo.2010.171)

30 Renehan AG, Zwahlen M, Minder C, O'Dwyer ST, Shalet SM \& Egger M. Insulin-like growth factor (IGF)-I, IGF binding protein-3, and cancer risk: systematic review and meta-regression analysis. Lancet 2004363 1346-1353. (doi:10.1016/S0140-6736(04)16044-3)

31 Gazzaruso C, Gola M, Karamouzis I, Giubbini R \& Giustina A. Cardiovascular risk in adult patients with growth hormone (GH) deficiency and following substitution with GH - an update. Journal of Clinical Endocrinology and Metabolism 201499 18-29. (doi:10.1210/ jc.2013-2394)

32 Olsson DS, Andersson E, Bryngelsson IL, Nilsson AG \& Johannsson G. Excess mortality and morbidity in patients with craniopharyngioma, especially in patients with childhood onset: a population-based study in sweden. Journal of Clinical Endocrinology and Metabolism 2015100 467-474. (doi:10.1210/jc.2014-3525)

Received 26 May 2016

Revised version received 14 October 2016

Accepted 21 October 2016 